\title{
Peripheral Nerve Stimulator (PNS) Versus Trans- Arterial (TA) Techniques for Axillary Brachial Plexus Block
}

\author{
Sunil Kumar Sah ${ }^{1}$, Tofazzel Haque Sahana ${ }^{2}$, Sekhar Ranjan Basu ${ }^{3}$ \\ ${ }^{1}$ Assist. Professor, North Bengal Medical College; Darjeeling, West Bengal, India \\ ${ }^{2}$ SR, Department of Anaesthesiology; North Bengal Medical College; Darjeeling, West Bengal, India \\ ${ }^{3}$ HOD, North Bengal Medical College; Darjeeling, West Bengal, India
}

Corresponding Author: Tofazzel Haque Sahana

\section{ABSTRACT}

Background: Axillary brachial plexus block is one of the widely used techniques for upper extremity surgery. Peripheral nerve blocks (PNB) provide optimal surgical conditions while providing prolonged post-operative analgesia. The transarterial (TA) technique of axillary brachial plexus block is a well established method of producing regional anaesthesia for surgeries at or below elbow. In this prospective randomized study we compared, "peripheral nerve stimulator (PNS) versus trans-arterial (TA) techniques for axillary brachial plexus block"

Methods: In this prospective, randomized study 80 patients, age $>18$ year, ASA-I \& II, were divided randomly into two groups PNS and TA. In PNS groups 40 patients received axillary approach of brachial plexus block with the help of peripheral nerve stimulator, and rest TA group received axillary block through transarterial approach. Local anaesthetic $0.25 \%$ bupivacaine $15 \mathrm{ml}+1 \%$ lignocaine with adrenaline $(1: 200,000) 20 \mathrm{ml}$ was used. Then success rate of two different methods of block were compared. Other parameters of comparison was block performance time of block, onset of sensory and motor block, failure rate, analgesia required etcetera.

Results: The success rate of the block in PNS group was $90 \%$ and the success rate of TA group was $85 \%$ and there was no significant difference in success rate. Performance time was significantly low in trans-arterial axillary approach of brachial plexus block $(\mathrm{p}<0.005)$. There was no significant difference in onset of motor and sensory block. The sensory and motor functions returned properly in all patients.
Conclusion: In our study we found that the PNS guided axillary block and TA injection axillary brachial plexus block provide similar success rate, and onset of block when musculocutaneous nerve blocked separately in the both techniques.

Keywords: Axillary brachial plexus block, Trans-arterial approach, Peripheral nerve stimulator.

\section{INTRODUCTION}

Peripheral nerve blocks (PNB) are frequently used techniques in upper extremity surgery. PNB provides optimal surgical conditions while providing prolonged post-operative analgesia. ${ }^{[1]}$ For superior extremity surgery brachial plexus block is preferred due to its advantage as application with ease with lower complication rate. ${ }^{[2]}$ There are several approaches of brachial plexus block that is interscalene, supraclavicular, infraclavicular, and axillary. Peripheral nerve stimulator (PNS) was considered as the gold standard technique for nerve location. Other methods of the location of brachial plexus (axillary approach) include loss of resistance, trans-arterial (TA) injections, elicitation of paraesthesia and ultrasonographic techniques. ${ }^{[3-5]}$ PNS with double injection technique has a success rate of 85 to $95 \%$ when musculocutaneous nerve blocked separately. For a successful block local anaesthetic solution should be injected into the nerve sheath rather than directly into the nerve. ${ }^{[6]}$ According to De Jong, ${ }^{[2]}$ 
the estimated volume of brachial plexus sheath is $42 \mathrm{ml}$. Partridge and co-workers confirmed the presence of multiple compartments, they concluded that the septa dividing them were incomplete based on injection of methylene blue and latex solution into cadavers. ${ }^{[7]}$ Axillary block is a technique of placing adequate quantity (Approximately 35 to $40 \mathrm{ml}$ ) local anaesthetic around the brachial plexus sheath which is located in the axilla. It has several advantages in patients with significant co-existing morbidity, the advantages includes simplicity of administration, sympathetic blockade, attenuation of stress response, minimal respiratory impairment, less post-operative nausea vomiting (PONV), and early restoration of feeding as well as early mobilization. Axillary block is also the safest of the four main approaches to the brachial plexus, as it does not risk paresis of the phrenic nerve, nor does it have the potential to cause pneumothorax. Axillary approach to the brachial plexus employed to provide regional anaesthesia or as an analgesic technique to be used in combination with general anaesthesia. The TA technique of axillary brachial plexus block is a well established technique of regional anaesthesia for surgeries at or below elbow. ${ }^{[8]}$ TA approach is technically less difficult reportedly result in more reliable block compared to other approaches. The failure rate of TA approach is around 20 to $35 \%$. ${ }^{[9-10]}$ Regardless of techniques used, it is essential to block the musculocutaneous nerve block separately with 5-10 ml local anaesthetic.

\section{METHODS}

After taking institutional ethical committee clearance and written informed patient's consent, the study was conducted in our hospital from 2015-2016 over a period of 14 months. Patients with more than 18 years with ASA physical status I-II undergone surgeries at or below elbow were included in the study group after considering the exclusion criteria.(Patient refusal, coagulopathy, pre existing peripheral neuropathy, diabetes mellitus and other metabolic disorders, history of local anaesthetic allergy, local anatomical deformity etc)

Patients were randomly allocated to either PNS group $(n=40)$ or TA group $(n=40)$ using a computer generated random numbers. In the procedure room, after giving premedication with intravenous midazolam $(0.03 \mathrm{mg} / \mathrm{kg})$, patients were monitored by pulse oximetry, heart rate, and non-invasive blood pressure throughout the procedure. The patients were placed in supine position with the arm abducted perpendicular to the body. In TA technique after palpation of axillary pulse the overlying skin was infiltrated with $1 \%$ lignocaine with a $25 \mathrm{~mm} 25$ gauge hypodermic needle then with 22 gauge needle was introduced, once blood is aspirated; go "through" the artery. Once aspiration was negative, half amount of local anaesthetic injected into the posterior aspect of the artery, rest into the anterior aspect of the artery after repeated negative aspiration. In our study we used $0.25 \%$ bupivacaine $15 \mathrm{ml}+1 \%$ lignocaine $20 \mathrm{ml}$. In PNS groups, nerve location was performed with a nerve stimulator (Plexigon, Vygon, Italy) using a 22 -gauge, $30^{\circ}$ short bevelled 5 -cm long Teflon-coated needle (Locoplex, Vygon, UK).The initial setting of nerve stimulator was set with a pulse duration of $0.15 \mathrm{~ms}$, the current intensity $0.2-0.5 \mathrm{~mA}$, and a frequency of $2 \mathrm{~Hz}$. Radial, ulnar, median and musculocutaneous nerves were located according to the specific twitch responses elicited by their stimulation. The needle was repositioned if patient complains of severe pain and no fade of motor response after injecting 1-2ml of LA.

An experienced anaesthesiologist, who was unaware of the block techniques, recorded the onset of sensory and motor blocks every $1 \mathrm{~min}$ up to the complete or incomplete block time. Sensory block was assessed as loss of pinprick sensation in the area sensory distribution of each nerve with the contra lateral unblocked side as control. 
Normal sensation-no block; touch sensation, but no pain-partial block; total loss of sensation-complete block. Motor block was evaluated using forearm and wrist flexion/extension, and pinching of fingers. No loss of force-no block; reduced force as compared with contra lateral arm-partial block; incapacity to overcome gravitycomplete motor block. The zero time for the onset of sensory and motor block was the completion of local anaesthetic solution injection. Time to readiness for operative interventions (complete sensory block and complete motor block in at least three of four nerves with partial motor block in the remaining nerve) was recorded. In case of pain, supplementary analgesia with $1 \mathrm{mcg} / \mathrm{kg}$ slow intravenous fentanyl was given. The need for more than $100 \mathrm{mcg}$ fentanyl to complete surgery was considered as an insufficient block. If fentanyl supplementation (maximum 200mcg) was not sufficient for surgery, general anaesthesia was administered via laryngeal mask airway. Post operative analgesia was provided with intra muscular injection of diclofenac sodium 75mg. Additional sedation was given with slow intravenous diazepam $5 \mathrm{mg}$.
Post operative recovery was checked, and the incidences of adverse event (paraesthesia, dysaesthesia or motor deficits) were recorded, primary outcome was the block success at 15 and 30 minute. Other parameter were time to perform the block, number of attempts, time taken to reach surgical anaesthesia, duration of sensory and motor block, time to first analgesic demand. Statistical analysis was performed using Z-test. Discrete variables like age, sex, gender were analysed by using Chi-squire test. Variables were presented as mean \pm standard deviation (SD) categorical data are presented as number (\%) while number of skin punctures and needle redirections as median(range). A $p<0.05$ was considered as significant. Power calculations were based on the SD reported in previous investigations with multiple injection techniques for axillary brachial plexus, type1 error of $5 \%(\alpha=0.05)$ and power of study $80 \%(1-\beta=0.8)$ expecting a $15 \%$ difference of success rate in TA block with PNS and expecting 10\% drop-out rate; total 80 patients were included in our study. Data were calculated using Quick Calcsgraph Pad Software.

\section{RESULTS}

Table1: Demographic data

\begin{tabular}{|l|l|c|c|c|}
\hline & & $\begin{array}{c}\text { Group PNS } \\
(\mathbf{n = 4 0})\end{array}$ & $\begin{array}{c}\text { Group TA } \\
(\mathbf{n = 4 0})\end{array}$ & P value \\
\hline Age (years) & & $37.75 \pm 11.94$ & $42.32 \pm 10.62$ & $0.07 \mathrm{NS}$ \\
\hline Sex & Males & 32 & 29 & \\
\hline & Females & 8 & 11 & \\
\hline Weight $(\mathrm{kg})$ & & $67.35 \pm 7.32$ & $66.04 \pm 8.49$ & $0.46 \mathrm{NS}$ \\
\hline Height $(\mathrm{m})$ & & $172.17 \pm 7.35$ & $170.95 \pm 8.7$ & $0.50 \mathrm{NS}$ \\
\hline BMI $(\mathrm{kg} / \mathrm{m} 2)$ & & $25.00 \pm 2.34$ & $24.81 \pm 2.78$ & $0.74 \mathrm{NS}$ \\
\hline
\end{tabular}

Values are mean \pm SD. There was no significant difference between groups ( $p>0.05)$.Group PNS: Peripheral nerve stimulator guided block. Group TA: Transarterial block. NS-No significant difference

Table 2: Block performance time significantly less in Transarterial technique. Onset of sensory and motor block time was not significantly different.

\begin{tabular}{|l|c|c|c|}
\hline & $\begin{array}{c}\text { Group PNS } \\
(\mathbf{n = 4 0})\end{array}$ & $\begin{array}{c}\text { Group TA } \\
(\mathbf{n = 4 0 )}\end{array}$ & P value \\
\hline Block Performance Time(Min) & $3.025 \pm 0.93$ & $2.35 \pm 0.69$ & $<0.005$ \\
\hline Sensory Block Onset Time & $14.20 \pm 4.96$ & $15.6 \pm 2.00$ & 0.1048 \\
\hline Motor Block Onset Time & $17.19 \pm 2.71$ & $18.2 \pm 2.86$ & 0.1090 \\
\hline
\end{tabular}

There were no differences in age and weight of the patients between the two groups. In both groups the number of male patient was more than female patients. The number of skin punctures was less in TA group than PNS group. TA group requires 
fewer needle redirections than PNS group. No differences were observed in the onset of sensory and motor block or readiness to surgery. Failed block requiring general anaesthesia was nil in either group.
Insufficient block was reported $12.5 \%$ patients in PNS group and $17.5 \%$ patients in TA group. No neurological complications were reported at the 24-hour follow-up period.

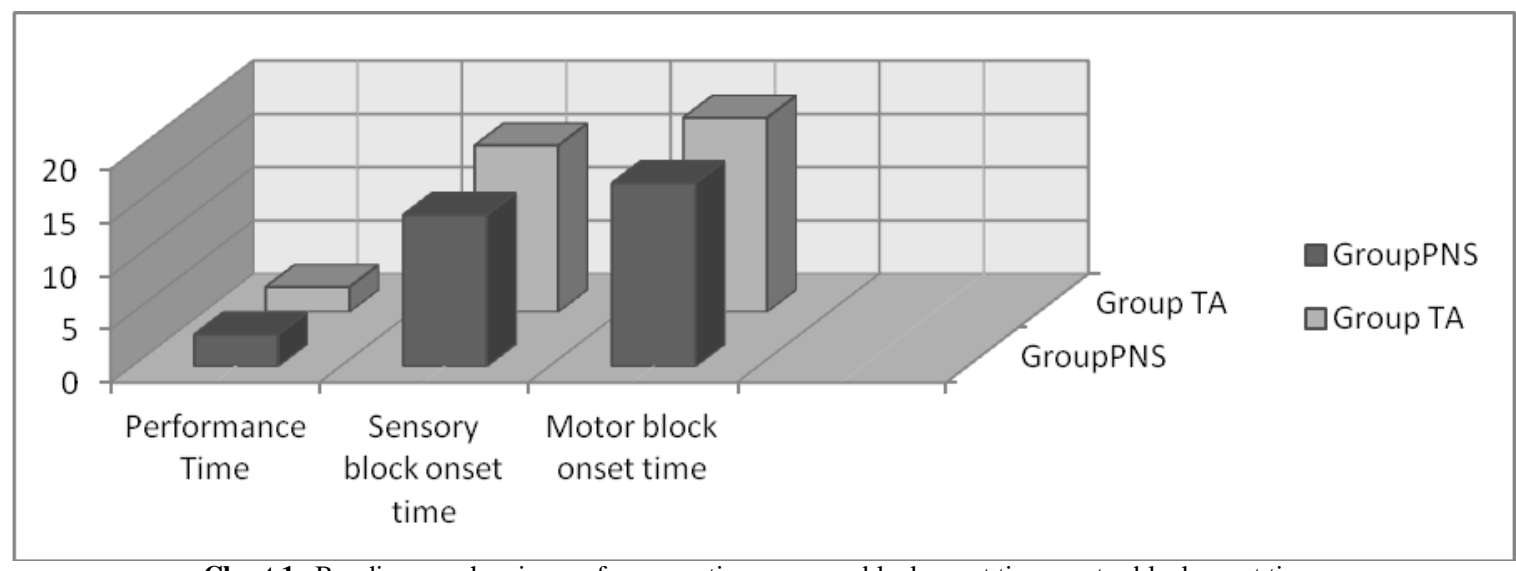

Chart 1: Bar diagram showing performance time, sensory block onset time, motor block onset time.

Table 3: Showing the success rate and insufficient block of the patients in Group PNS and TA group.

\begin{tabular}{|c|c|c|c|}
\hline & $\begin{array}{c}\text { Group PNS } \\
(\mathbf{n = 4 0})\end{array}$ & $\begin{array}{c}\text { Group TA } \\
(\mathbf{n = 4 0})\end{array}$ & P value \\
\hline $\begin{array}{c}\text { Successful Block } \\
\text { (In Percentage) }\end{array}$ & $35(87.5 \%)$ & $33(82.5 \%)$ & 0.85 \\
\hline Insufficient block & $5(12.5 \%)$ & $7(17.5 \%)$ & 0.75 \\
\hline
\end{tabular}

Table 4: Showing the requirement of additional analgesia and sedation to the patients in group PNS and group TA.

\begin{tabular}{|l|c|c|c|}
\hline & $\begin{array}{c}\text { Group N } \\
(\mathbf{n = 3 5})\end{array}$ & $\begin{array}{c}\text { Group T } \\
(\mathbf{n = 3 3 )}\end{array}$ & P value \\
\hline $\begin{array}{l}\text { Additional fentanyl } \\
\text { requirement }\end{array}$ & $5(14.15 \%)$ & $4(8.25 \%)$ & 1.0 \\
\hline $\begin{array}{l}\text { Additional sedation } \\
\text { requirement }\end{array}$ & $7(20 \%)$ & $7(21.22 \%)$ & 1.0 \\
\hline
\end{tabular}

\section{DISCUSSION}

The various methods of nerve location were based on either evocation of paraesthesia or identification of motor response of individual nerve on PNS. A transarterial technique does not require evocation of paraesthesia. A transarterial technique can be used, whereby the needle pierces the artery and 40 to $50 \mathrm{~mL}$ of solution is injected posterior to the artery. Alternatively, half of the solution is injected posterior and half is injected anterior to the artery. ${ }^{[11]}$ In our study, we injected half amount of local anaesthetic solution posterior to the artery and rest amount anterior half of the artery. Great care must be taken to avoid intravascular injection with this technique, particularly because the pressure of injection within the compartments of the axillary sheath may move anatomic structures in relation to the immobile needle. The paresthesia and TA approach of brachial plexus block are not free from complications and failure. There has been a shift in the established methods of nerve location from elicitation of paresthesia to identification of the proper motor response on PNS. PNS with double injection technique has a success rate of $85 \%$ to $95 \%$ when musculocutaneous nerve block separately. ${ }^{[12]}$ Musculocutaneous nerve was blocked separately in both study groups. TA technique has the risk of hematoma formation and possible intravenous injection. ${ }^{[8]}$ The PNS techniques has the possibility of inadvertent neurovascular damage. ${ }^{[9]}$ Yanil et al ${ }^{[13]}$ in their single injection axillary block technique, concluded that it was more advantageous than multiple injection. The success rate for an axillary block depends on the definition of a successful block (i.e., surgical anesthesia versus blockade of all four terminal nerves of the upper extremity), the technique used to localize the brachial plexus, and the number of injections. Success rates with single injection techniques can vary. ${ }^{[14]}$ Thompson and Rorie ${ }^{[15]}$ concluded that the presence of multiple compartments limits diffusion of 
the local anesthetic (and the success of single injection compared to multiple injection techniques). Although Partridge and co-workers 40 confirmed the presence of these compartments, they concluded that the "septa" dividing them were incomplete based on injections of methylene blue and latex solutions into cadavers. The controversy-surrounding single-versus multiple-injection techniques remains unresolved. Terri S. Jones ${ }^{[16]}$ in her study concluded both TA and PNS techniques have similar success rate. Eliciting a paresthesia is as efficacious as peripheral nerve stimulation (with a motor response of 0.5 to $1.0 \mathrm{~mA}$ ). Previous studies have examined safety, demonstrating no increased toxicity with mixture of bupivacaine and lidocaine. ${ }^{[17]}$ Research has also examined the use of multiple combinations of local anaesthetics including bupivacaine and lignocaine in nerve and spinal block. ${ }^{[18-19]}$

In general, the efficacy of paresthesia and peripheral nerve stimulator techniques increases when multiple injections are used. Conversely, success rates with perivascular or fascial click approaches are variously reliable. [5] $\mathrm{We}$ studied success rate of TA versus double injection PNS guided nerve block. The success rate of both techniques was similar. There was no difference in the sensory and motor block onset time.

\section{CONCLUSION}

We studied success rate of TA versus double injection PNS guided nerve block. The success rate of both techniques was similar. We used $0.25 \%$ bupivacaine $15 \mathrm{ml}+1 \%$ lignocaine with adrenaline $(1: 200,000) 20 \mathrm{ml}$. There was no difference in the sensory and motor block onset time. Significance difference was present in the performance time of block.

\section{REFERENCES}

1. Local anaesthetic techniques. In: Aitkenhead AR, Moppett IK, Thompson PJ editors. Smit and Aitkenhead's Textbook of
Anaesthesia, $6^{\text {th }}$ edition. London: Elsevier Churchill Livingstone: 2013.pp. 540-42.

2. De Jong RH. Axillary block of the brachial plexus.Anesthesiology 1961; 22:215-25.

3. Satapathy AR, Coventry DM. Axillary brachial plexus block. Anesthesia Res Pract 2011; 2011:173796.

4. Coventry DM, Barker KF, Thompson M. Comparison of two neurostimulation techniques for axillary brachial plexus blockade. Br J Anaesth 2001; 86:80-83.

5. Neal JM, Gerancher JC, Hebal JR, Ilfeld $\mathrm{BM}$, McCartney CJ, Franco CD, et al. Upper extremity regional anaesthesia: essentials of current understanding 2008. Reg Anaesth Pain Med 2009; 34:134-70.

6. Marhofer P, Greher M, Kapral S. Ultrasound guidance inregional anaesthesia. Br J Anaesth 2005; 94:7-17.

7. Partridge BL, Katz J, Benirschke K. Functional anatomy of the brachial plexus sheath: implications for anesthesia. Anesthesiology. 1987; 66:743-747.

8. Davis WL, Lennon RL, Wedel DJ. Brachial plexus anesthesia for outpatient surgical procedure on upper extremity. Mayo Clin Proc. 1991; 66:470-73.

9. Finucane BT. Complications of brachial plexus anesthesia. In: Finucane BT, editor. Complications of regional anaesthesia. $2^{\text {nd }}$ edition. Philadelphia, Churchill Livingstone; 1999.pp.56-76.

10. Cockings E, Moore PL, Lewis RC. Transarterial brachial plexus blockade using high dose of $1.5 \%$ mepivacaine. Reg Anesth. 1987; 12:159-164.

11. Horlocker TT, Kopp SL, Wedel DJ. Peripheral nerve block. In: Miller RD, Cohen NH, Eriksson LI, Fleisher LA, Kronish JP, Young WL, et al editors. Millar's Anesthesia. $8^{\text {th }}$ edition. Philadelphia: Elsevier 2015.pp.1729-30.

12. Inberg P, Annila I, Annila P. Double injection method using peripheral nerve stimulator to single injection in axillary plexus block. Reg Anesth. Pain Med 1999; 24:509-13.

13. Yanil Y, Ozdemir M, Bakan N.Our experiences with a single injection axillary block technique. North Clin Istanbul 2014; 1:39-44

14. Baranowski AP, Pither CE: A comparison of three methods of axillary brachial plexus anaesthesia, Anaesthesia.1990; 45:362. 
Sunil Kumar Sah et.al. Peripheral nerve stimulator (PNS) versus trans-arterial (TA) techniques for axillary brachial plexus block

15. Thompson GE, Rorie DK: Functional anatomy of the brachial plexus sheaths, Anesthesiology.1983; 59:117.

16. Jones TS, Comparison of axillary block techniques: Is there a difference in success rates? 1997; 65:257-59.

17. De Jong RH, Bonin JD. Mixtures of local anesthetics are no more toxic than the parent drugs. Anesthesiology.1981; 54:177-81.

18. Brodsky JB, Brock-Utne JG. Mixing local anaesthetics.Br J Anaesth.1978; 50:1269.
19. Bromage PR, Gertel M. Improved brachial plexus blockade with bupivacaine hydrochloride and carbonated lidocaine. Anesthesiology.1972; 36:479-87.

How to cite this article: Sah SK, Sahana TH, Basu SR. Peripheral nerve stimulator (PNS) versus trans-arterial (TA) techniques for axillary brachial plexus block. Gal Int J Health Sci Res. 2021; 6(1): 21-26. 